\title{
Within-Plant Migration of the Predatory Mite Typhlodromalus aripo from the Apex to the Leaves of Cassava: Response to Day-Night Cycle, Prey Location and Prey Density
}

\author{
Alexis Onzo • Rachid Hanna • Maurice W. Sabelis
}

Revised: 26 June 2008 / Accepted: 9 October 2008 /

Published online: 24 October 2008

(C) The Author(s) 2008. This artcle is published with open access at Springerlink.com

\begin{abstract}
Under attack by herbivores, plants produce a blend of "herbivore-induced plant volatiles (HIPV)" that help natural enemies of herbivores locating their prey, thereby helping plants to reduce damage from herbivory. The amount of HIPV emitted by plants increases with herbivore density and is positively correlated with the intensity of the olfactory response of natural enemies. In this study, we determined the effects of density or within-plant distribution of the herbivorous mite Mononychellus tanajoa on movement of the predatory mite Typhlodromalus aripo out of apices of cassava plants. Proportions of T. aripo that migrated out of apex, and distances traveled were significantly higher when $M$. tanajoa was further away from the apex - i.e. on middle or bottom leaves of cassava plants - than when present on top leaves, or absent from the plant. This supports previous field observations that $T$. aripo is not a sit-and-wait predator but uses HIPV to search and locate its prey within cassava plant.
\end{abstract}

Keywords Phytoseiidae $\cdot$ Mononychellus tanajoa $\cdot$ herbivore-induced plant volatiles $(\mathrm{HIPV}) \cdot$ tritrophic interactions $\cdot$ olfactory response

\footnotetext{
A. Onzo • R. Hanna

Biological Control Centre for Africa, International Institute of Tropical Agriculture, 08 B.P. 0932, Cotonou, Benin, West Africa
}

\section{A. Onzo • M. W. Sabelis}

Institute for Biodiversity and Ecosystem Dynamics, University of Amsterdam, Kruislaan 320, 1098 SM Amsterdam, The Netherlands

\author{
A. Onzo $(\bowtie)$ \\ IITA-Benin, c/o L. W. Lambourn, 26 Dingwall Road, Croydon CR9 3EE, UK \\ e-mail: a.onzo@cgiar.org
}




\section{Introduction}

In biological control programs involving the use of predators or parasitoids against herbivorous arthropods, plants have been often considered as passive players in that their impact on predator-prey (or parasitoid-host) interactions is not made explicit in developing control strategies. During the last two decades, ecologists have become fully aware that plants can effectively defend themselves against herbivorous arthropods, either directly, by limiting feeding by herbivores; or indirectly, by promoting the effectiveness of natural enemies of the herbivores (Price et al. 1980; Dicke and Sabelis 1988; Sabelis et al. 1999a,b,c; Cortesero et al. 2000; Sabelis et al. 2001, 2005). Direct defenses include plant structures (such as thick cuticle, 'slippery' cuticle surfaces, leaves covered by a dense layer of trichomes, or by glandular trichomes), that reduce feeding by the herbivore, and secondary plant compounds that inhibit digestion, intoxicate or deter the herbivore. The indirect strategy is based on a "mutualistic" association between plants and the herbivores' natural enemies, in which plants attract natural enemies through chemical lures, provide them with alternative food such as exudates, pollen or nectar. Plants can also develop shelters, called "domatia", that protect natural enemies against harsh environmental conditions or against relatively large hyper-predators (e.g. Sabelis et al. 1999a).

It is well known by now that, in response to attack by herbivores, plants can produce a blend of "herbivore-induced plant volatiles (HIPV)" that attract natural enemies of the herbivores and arrest them on or near the plants under attack. These HIPV help the natural enemies in locating their victims (Dicke and Sabelis 1988; Dicke et al. 1998), thereby reducing herbivore load of the plant. The strength of the attraction of natural enemies to plants, and the efficacy of natural enemies against the herbivores are generally enhanced by the existence of domatia on the plants. For example, plants with domatia are more likely to be inhabited by a predatory mite and, generally, have many more predators per leaf compared with sympatric plants lacking these structures (Grostal and O'Dowd 1994; Rozario 1995). As a consequence, plants with domatia harbour less herbivorous mites compared to plants that lack domatia (Agrawal 1997). Predators in domatia help the plant to defend itself against herbivores and in turn, domatia protect predators from their arthropod natural enemies or abiotic stress (Walter and O'Dowd 1992; Norton et al., 2001).

The apex (i.e. the growing point) of a cassava plant plays a role similar to that of domatia, as the predatory mite Typhlodromalus aripo De Leon hides in the apex during the day and comes out to actively forage for the herbivorous mite Mononychellus tanajoa (Bondar), on young cassava leaves during night hours (Onzo et al., 2003). Hiding in the apex is thought to protect the predatory mite against harsh environmental conditions such as low relative humidity and direct exposure to ultraviolet (UV) radiations, especially UVB, which are harmful to the predator (Onzo et al., in preparation). Previous studies (Gnanvossou et al. 2001, 2003) showed that $T$. aripo is attracted to volatiles emitted by cassava leaves or apices infested by $M$. tanajoa. It is still not clear, however, if density and withinplant location of $M$. tanajoa on cassava plants affect both the proportion of T. aripo that migrate from the apex at night and the distance covered by the migrating predators during their foraging bouts along cassava plants. In a tritrophic system consisting of the kidney bean plant, the two-spotted mite Tetranychus urticae Koch 
and the predatory mite Phytoseiulus persimilis Athias-Henriot, Maeda and Takabayashi (2001) found that the amount of HIPV emitted by the plant changed in relation to changes in T. urticae density on the plant. They also showed that the intensity of the olfactory response of $P$. persimilis correlates positively with the amount of volatiles emitted by the plant. Such a mechanism may well influence the movement of $T$. aripo out of the apices of cassava plants at night. If this is the case, the quantity of HIPV emitted by a cassava plant should be proportional to the density of $M$. tanajoa per plant and the olfactory response of $T$. aripo should be proportional to the quantity of HIPV emitted by the cassava plants under attack by $M$. tanajoa. We therefore, hypothesize that: (1) the number of T. aripo that leaves the apex to forage on cassava leaves during night hours increases with prey population on the plant; and (2) the distance traveled by $T$. aripo during its foraging bouts increases with the distance of the prey patch to the apex of the cassava plant. Here, we present the results of experiments aimed at testing these two hypotheses.

\section{Materials and Methods}

Two experiments were conducted in a screenhouse at IITA-Benin Station (Cotonou). Cassava cuttings (20 cm long) of the variety "Agric" were planted singly in plastic pots (14 cm diameter at the base, $20 \mathrm{~cm}$ at the top and $17.5 \mathrm{~cm}$ high), filled with $\mathrm{c}$. $3.8 \mathrm{~kg}$ of topsoil collected from a field that was in fallow for more than 4 years. The potted plants were transferred to the screenhouse just after planting and placed on $350 \times 180 \times 76 \mathrm{~cm}(L \times W \times H)$ iron benches which were separated from each over by a distant of $65 \mathrm{~cm}$. To accommodate all treatments and replicates, each bench was divided into two compartments. Each compartment accommodated one replicate of a treatment. Where needed, plants were thinned to one stem per cutting at two weeks after planting to establish a uniform plant size across treatments and replicates.

\section{Experiment 1: Effects of Prey Location on Foraging by T. aripo}

This experiment was designed to test whether the location of $M$. tanajoa within a cassava plant influences the movement of T. aripo out of the apex, in response to HIPV emitted by the leaves. The hypothesis is that the further the prey patch is from the apex of the cassava plant, the lower the amount of volatiles that would reach the predator and the weaker the response of T. aripo to the chemical cues. The predator's response can be measured by the number of T. aripo that emigrated from the apex of the cassava plant. With this experiment we also intended to test the ability of T. aripo to track the origin of the HIPV to discover an M. tanajoa patch within the cassava plant. This could be measured by the distance covered by foraging $T$. aripo in response to different positioning of $M$. tanajoa patches within the cassava plant.

For this experiment, potted cassava plants bearing at least ten leaves were used, and the treatments were based on the location of $M$. tanajoa within the cassava plant. The cassava canopy was, therefore, divided into three parts as follows: top leaves, middle leaves and bottom leaves. Taking the apex as the starting point, top leaves were represented by leaf 1 and 2; middle leaves by leaf 5 and 6; and bottom leaves by leaf 9 and 10 . 
The four treatments of these experiments consisted of: (1) control with no $M$. tanajoa on plants; (2) plants with top leaves infested with M. tanajoa; (3) plants with middle leaves infested with M. tanajoa; and (4) plants with bottom leaves infested with $M$. tanajoa. Each treatment was replicated three times and each replicate was represented by four potted cassava plants. The four plants in each replicate were placed at least $80 \mathrm{~cm}$ apart. Treatments and replicates were assigned randomly to bench compartments.

For the treatments with $M$. tanajoa (i.e. treatments 2, 3, and 4), 200 adult $M$. tanajoa - originating from wild populations and reared on potted cassava plants in a screenhouse for 2 to 3 weeks before use-were added to the cassava plants $72 \mathrm{~h}$ before the day of observation, when potted cassava plants were 8 weeks old. This time period is enough to induce damage to cassava leaves as a consequence of mite feeding activities (Gnanvossou et al. 2001). To prevent the mites from dispersing throughout the plant, a double-side sticky tape was fixed around the stem, just above the petiole of the highest infested leaf, and also below the petiole of the lowest infested leaf. In this manner, mite-feeding activities were restricted, almost exclusively, to the infested leaves.

In each treatment, 15 adult female T. aripo-collected from a cassava field on the previous day - were released on each cassava plant around noon of the day when the observations were initiated. After releasing the predator on the plants, the doublesided sticky tape was removed from the plants to allow free movement of the predatory mites. The experiment was repeated twice, between 29 June and 03 August 2006; and between 05 September and 25 October 2006.

\section{Experiment 2: Effects of Prey Density on Movement of T. aripo Out of Apex of Cassava Plants}

This experiment was intended to test whether the number of T. aripo moving out of the apex at night depended on $M$. tanajoa density on the leaves. The hypothesis here is that the response of $T$. aripo to HIPV emitted by $M$. tanajoa-infested cassava plants will increase with increasing $M$. tanajoa density on the plants, as the amount of HIPV increases with prey (=herbivore) density on the plant (Gnanvossou et al. 2001).

The three treatments of this experiment consisted of: (1) control with no $M$. tanajoa on the plants; (2) high prey density (i.e. predator-to-prey ratio of c. 1:200); and (3) low prey density (i.e. predator-to-prey ratio of c. 1:20). Each treatment was replicated three times and each replicate was represented by six potted cassava plants. The six plants in each replicate were at least $80 \mathrm{~cm}$ apart. Treatments and replicates were assigned to bench compartments at random.

Three weeks after planting, all plants were pruned to ten leaves; thereafter, plants assigned to the high prey density treatment were infested with ten adult female $M$. tanajoa that were placed on the youngest leaves. Plants assigned to the low prey density treatment were similarly infested but one week later (i.e. four weeks after planting) than the high prey density treatment. To determine the number of T. aripo to be released to meet the required predator-to-prey ratio, mean $M$. tanajoa density on each category of plants (i.e. low or high density) was estimated from a subsample of ten plants per prey density treatment level, at one week after the last 
infestation (i.e. 5weeks after planting). On the next day around 1000 hours in the morning, 15 adult female T. aripo were added to each plant. Observations of the within-plant movement of predators started 1 day later. Female $M$. tanajoa used in this experiment had been collected from cassava fields in southern Benin and maintained on potted cassava plants for two weeks, while T. aripo were collected from a cassava field one day before their addition to the experimental cassava plants. The experiment was conducted between 05 September and 12 October 2006.

\section{Data Collection and Analysis}

For experiment one-i.e. M. tanajoa location within cassava plant-six plants were sampled per treatment (two per replicate) at 2200 hours on the day of T. aripo release, and at 2000 hours the following day. For experiment two-i.e. M. tanajoa density on cassava plant-nine plants (three per replicate) were sampled per treatment at 2000 hours and at 0000 hours on the day following T. aripo addition. For each selected plant, the apex was removed and immediately placed into an individual glass vial containing 70\% ethanol. The apices were later dissected under a binocular microscope to facilitate T. aripo counting - mobile stages only. The leaves were removed, with their petiole, starting from leaf 1 (i.e. the nearest leaf to the apex), down to the lowest. All leaves were immediately checked under binocular microscope and all stages of M. tanajoa and T. aripo on the leaves were counted and recorded separately for leaf position per plant.

To determine whether T. aripo's emigration from the apex was related to the location of $M$. tanajoa within the cassava plant, or to the density of $M$. tanajoa on the plant, the proportions of $T$. aripo that emigrated from the apex and was effectively found on leaves were calculated per plant and per treatment. In addition, the distance covered by the foraging $T$. aripo (i.e. the mean leaf position visited by the predator below the apex), was calculated as a weighted leaf number $(L)$, using the following formula (Onzo et al. 2003):

$$
L=\sum_{x=0}^{y} x N(x) / \sum_{x=0}^{y} N(x)
$$

with $x=$ leaf position (ranging from the apex (leaf 0 ) to the $y$ th leaf below the apex), $y=$ total number of leaves on the plant $(10<y<12)$, and $N(x)=$ number of mobile $T$. aripo on leaf $x$.

For experiment one (i.e. M. tanajoa location within cassava plant), proportions of emigrated T. aripo and distances covered (i.e. weighted leaf numbers) were compared among $M$. tanajoa locations, sampling days and sampling hours (nested within sampling day), using analysis of variance (SAS 2003). For experiment two (i.e. M. tanajoa density on cassava plant), proportions of emigrated T. aripo and distances covered were compared among M. tanajoa density levels and sampling hours. When differences were statistically significant, treatment means were separated using the Student-Newman-Keuls multiple range test. Data on proportion were arcsine-square root-transformed before the statistical analysis. 


\section{Results}

\section{Effects of Prey Location on Foraging by T. aripo}

The migration of T. aripo from the apex to cassava leaves during night foraging bouts depended on within-plant location of $M$. tanajoa on the cassava plant (Table 1). The proportions of T. aripo out of the apex during the night hours were significantly lower when $M$. tanajoa were not present on the plant, or were present on the top leaves, than when M. tanajoa was located on the middle or bottom leaves of the cassava plants. The proportions of T. aripo that migrated from the apex were similar when $M$. tanajoa were located on bottom or middle leaves and also similar when $M$. tanajoa were not present on the plant or present on the top leaves (Table 2).

The distance traveled by foraging $T$. aripo on cassava plants (i.e. the mean leaf position visited by the predator below the apex), also varied with the within-plant location of $M$. tanajoa (Table 1). This distance was significantly longer when $M$. tanajoa was located on the bottom leaves and middle leaves than when $M$. tanajoa was absent or located on the top leaves of cassava plants (Table 2).

Day, hours nested within day, and the interactions between day and within-plant location of $M$. tanajoa on cassava plants had no significant effects either on distance traveled by $T$. aripo or on the proportion of $T$. aripo that foraged at night (Table 1).

\section{Effects of Prey Density on Foraging by T. aripo}

The proportions of T. aripo that emigrated from apices of cassava plants at night did not differ among the three $M$. tanajoa density ranges tested (Table 3). Distance traveled by foraging predators at night also was not affected by the three $M$. tanajoa densities tested (Table 3). Hours and interaction between hours and density of $M$. tanajoa per plant did not significantly affect proportions of $T$. aripo emigrating from the apices, but the interaction term was bordering significance (Table 3). The latter result implies that $M$. tanajoa density might have an effect depending on the time of the day. Inspection of the data (Table 4) suggests that an effect on emigration of $T$. aripo out of the apex becomes manifest only at high $M$. tanajoa density. Average distance traveled by $T$. aripo away from the apex was lower when $M$. tanajoa density per plant was high compared with the low $M$. tanajoa density treatment, or when the plants were not infested with M. tanajoa; however, for both variables the differences were not statistically significant (Table 4).

Table 1 Effects of M. tanajoa Location Within Cassava Plants on Migration of T. aripo Out of Apex of Cassava Plants: ANOVA on Proportions of T. aripo Out of Apex and Distance Covered Within Cassava Plants

\begin{tabular}{|c|c|c|c|c|c|c|c|}
\hline \multirow[t]{2}{*}{ Source of variation } & \multirow[t]{2}{*}{$d f$} & \multicolumn{3}{|c|}{ Proportion of T. aripo on leaves } & \multicolumn{3}{|c|}{ Distance foraged by T.aripo } \\
\hline & & $M S$ & $F$ & $P$ & $M S$ & $F$ & $P$ \\
\hline Mt location & 3 & 0.224 & 5.52 & 0.002 & 4.975 & 4.48 & 0.006 \\
\hline Hours (day) & 2 & 0.041 & 1.00 & 0.373 & 2.565 & 2.31 & 0.105 \\
\hline Day & 1 & 0.000 & 0.01 & 0.924 & 2.042 & 1.84 & 0.179 \\
\hline Day $\times M t$ location & 3 & 0.040 & 0.99 & 0.401 & 0.191 & 0.17 & 0.915 \\
\hline
\end{tabular}


Table 2 Effects of $M$. tanajoa Location Within Cassava Plants on Migration of T. aripo Out of Apex of Cassava Plants: mean $( \pm \mathrm{SE})$ Separation Using Student-Newman-Keuls Multiple Range Test

\begin{tabular}{lcc}
\hline M. tanajoa location & Proportion of T. aripo on leaves & Distance foraged by T.aripo \\
\hline No M. tanajoa & $0.036 \pm 0.015 \mathrm{~b}$ & $0.313 \pm 0.103 \mathrm{~b}$ \\
On top leaves & $0.044 \pm 0.018 \mathrm{~b}$ & $0.375 \pm 0.118 \mathrm{~b}$ \\
On middle leaves & $0.116 \pm 0.026 \mathrm{a}$ & $0.903 \pm 0.328 \mathrm{ab}$ \\
On bottom leaves & $0.110 \pm 0.018 \mathrm{a}$ & $1.271 \pm 0.235 \mathrm{a}$ \\
\hline
\end{tabular}

\section{Discussion}

This study is among the few that have tested the role of HIPV in prey location by a predator species on whole plants under semi-field conditions. Several studies have been conducted in recent years to test the attraction of $T$. aripo to various odor sources, but most of them were laboratory-conducted olfactometer studies (Gnanvossou et al. 2001, 2003). Our study is the first that has attempted to explain how $T$. aripo locates its prey mite $M$. tanajoa within an intact cassava plant.

The series of screenhouse experiments presented in this study showed that, although the predatory mite $T$. aripo stays in the apex of cassava plants, it actively searches for and locates patches occupied by its main prey M. tanajoa. Indeed, both the proportion of $T$. aripo that emigrated from the apex at night and the distance covered by $T$. aripo while foraging along the stem of the cassava plant increased with the distance of the prey patch to the apex of the plant. In contrast, migratory movement of T. aripo out of the apex of the cassava plant is not affected by the density of M. tanajoa on the plant. Both the proportion of T. aripo that emigrated out of the apex and the distance traveled by $T$. aripo foraging at night were not statistically different among the three treatments. The relatively small proportion of T. aripo that emigrated from the apex of $M$. tanajoa-free plants and the relatively short distance that they traveled confirm that when the plant is not attacked by $M$. tanajoa, the olfactory stimuli that attract $T$. aripo out of the apex to the leaves are absent or very weak (Gnanvossou et al. 2001).

That T. aripo was able to locate a prey patch within the cassava plant, suggests that the predator could perceive the volatile cues emitted by the M. tanajoa-infested cassava leaves. Moreover, the differences in the migratory responses of T. aripo to the within-plant location of $M$. tanajoa suggest that the perception of the volatile cues by the predator is influenced by the distance that separates the odor source (i.e.

Table 3 Effects of $M$. tanajoa Density on Migration of $T$. aripo Out of Apex of Cassava Plants: ANOVA on Proportions of T. aripo Out of Apex and Distance Covered Within Cassava Plants

\begin{tabular}{|c|c|c|c|c|c|c|c|}
\hline \multirow[t]{2}{*}{ Source of variation } & \multirow[t]{2}{*}{$d f$} & \multicolumn{3}{|c|}{ Proportion of $T$. aripo on leaves } & \multicolumn{3}{|c|}{ Distance foraged by $T$. aripo } \\
\hline & & $M S$ & $F$ & $P$ & $M S$ & $F$ & $P$ \\
\hline M. tanajoa density & 3 & 0.001 & 0.01 & 0.990 & 0.775 & 1.15 & 0.324 \\
\hline Hours & 1 & 0.006 & 0.10 & 0.758 & 0.001 & 0.00 & 0.972 \\
\hline Hours $\times M t$ density & 3 & 0.168 & 2.71 & 0.077 & 1.138 & 1.69 & 0.195 \\
\hline
\end{tabular}


Table 4 Effects of $M$. tanajoa Density on Migration of T. aripo Out of Apex of Cassava Plants: mean $( \pm \mathrm{SE})$ Separation Using Student-Newman-Keuls Multiple Range Test

\begin{tabular}{lcc}
\hline M. tanajoa density & Proportion of $T$. aripo on leaves & Distance foraged by $T$. aripo \\
\hline No $M$. tanajoa & $0.125 \pm 0.024 \mathrm{a}$ & $1.023 \pm 0.224 \mathrm{a}$ \\
Low $M t$ density & $0.119 \pm 0.031 \mathrm{a}$ & $1.097 \pm 0.205 \mathrm{a}$ \\
High $M t$ density & $0.148 \pm 0.046 \mathrm{a}$ & $0.706 \pm 0.144 \mathrm{a}$ \\
\hline
\end{tabular}

the infested leaf) from the apex of the cassava plant. However, our data showed counterintuitively that the more distant the odor source, the higher the proportion of T. aripo that move out of the apex. Indeed, we would have expected that the closer the origin of the stimuli to the apex, the higher the perception of the cues and, consequently, the stronger the response from the predator. One possible explanation of this counterintuitive result may be that the closer the prey patch to the apex the higher the chance that $M$. tanajoa mobiles may reach the apex and arrest any migrating T. aripo. Whereas $M$. tanajoa is known to avoid leaves with $M$. tanajoa and T. aripo-possibly due to a predator-induced alarm pheromone of the spider mite-(Magalhães et al. 2002; Onzo et al. 2003), this may not have occurred in the experiments presented here because the apex was free of $M$. tanajoa at the time when $T$. aripo was released. So, M. tanajoa may well migrate from the top leaves to the apex in search for more nutritious leaves, thereby arresting T. aripo in the apex.

The non-significant impact of prey density on the responses of $T$. aripo to cues emitted from cassava plants infested by $M$. tanajoa is somewhat surprising, because average $M$. tanajoa density per plant is nearly 20 fold higher in the high density treatment than in the low density treatment. With such differences in prey densities, we expected the quantity of volatiles emitted by the cassava plant to be much higher in the high density treatment than in the low density treatment (Maeda and Takabayashi 2001), and that the olfactory response of the predator should increase with the quantity of HIPV emitted. More surprising is the lack of differences in the responses of the predators between $M$. tanajoa-free plants and $M$. tanajoa infested plants. An explanation for this finding could be that the flux of infochemicals was not efficiently directed towards the apex of the cassava plant, e.g. due to the turbulence of air movement in the screenhouse. However and as shown in Tables 3 and 4 , there is an almost significant effect of the interaction between hours and $M$. tanajoa density on the proportion of $T$. aripo out the apex, and this is an indication that the pattern of $T$. aripo migration is not similar during the two sampling hours. Indeed, scrutiny of the data showed that whereas $M$. tanajoa density did not significantly affect proportions of T. aripo out of the apex at 2000 hours, the sampling at 0000 hours showed that the proportions of migrating $T$. aripo were positively affected by $M$. tanajoa density. The average proportions of $T$. aripo that emigrated at 2000 hours were $0.39,0.31$ and 0.21 , respectively on plants without $M$. tanajoa, on plants with low and plants with high $M$. tanajoa densities. In contrast, at 0000 hours the proportions were $0.20,0.26$ and 0.39 , respectively on plants without $M$. tanajoa, on plants with low and on plant with high $M$. tanajoa densities. So, even though not significant, there is a trend for the proportion of T. aripo that emigrated from the apex to be higher when $M$. tanajoa density is high (see Tables 3 and 4 ). 
Although not significant, the distance traveled by migrating $T$. aripo at high $M$. tanajoa density was shorter than distances traveled at low M. tanajoa density or when the plants were $M$. tanjaoa-free (Table 4). An explanation for this finding could be that the predators were more efficient in finding cassava leaves with high $M$. tanajoa densities and skip visiting leaves lower in the plant.

Whereas the proportion of $T$. aripo that foraged on the cassava leaves were lower in our experiments than what is observed in the field (see Onzo et al. 2003), the study presented here shows and confirms that T. aripo is not a sit-and-wait predator. It also provides support for a role of HIPV in the prey searching strategy of T. aripo within cassava plants. However, because we used potted cassava plants of relatively small size, the response of $T$. aripo to volatile cues emitted by $M$. tanajoa-infested leaves may be different, had we used field plants of larger size that permit marked segregation of patches with the prey mite $M$. tanajoa. Despite these limitations, this study has improved our understanding of the foraging behavior of a predatory mite that plays a key role in the biological control of the cassava green mite in Africa (Yaninek and Hanna 2003; Hanna et al. 2005). In addition, these semi-field experiments constitute a major step toward testing the role of HIPV in sustaining predator-prey systems under field conditions. This is particularly important as most studies dealing with predator responses to prey odours are done under very artificial settings and their relevance to natural systems is often overlooked.

Acknowledgements The authors thank B. Bovis, H. Dossounon, R. Houndafotché and M. Adandé for their technical assistance; and two anonymous reviewers for their valuable comments and suggestions. This research was supported with funds provided to the International Institute of Tropical Agriculture (IITA) by the International Fund for Agricultural Development (IFAD), and with funds provided to the University of Amsterdam and IITA by the Netherlands Foundation for the Advancement of Tropical Research (WOTRO) in the form of a postdoctoral fellowship to A. Onzo.

Open Access This article is distributed under the terms of the Creative Commons Attribution Noncommercial License which permits any noncommercial use, distribution, and reproduction in any medium, provided the original author(s) and source are credited.

\section{References}

Agrawal AA (1997) Do leaf domatia mediate a plant-mite mutualism? An experimental test of the effects on predators and herbivores. Ecol Entomol 22:371-376

Cortesero AM, Stapel JO, Lewis WJ (2000) Understanding and manipulating plant attributes to enhance biological control. Biol Control 17:35-49

Dicke M, Sabelis MW (1988) How plants obtain predatory bodyguards. Neth J Zool 38:148-165

Dicke M, Takabayashi J, Posthumus MA, Schütte C, Krips OE (1998) Plant-phytoseiid interactions mediated by herbivore-induced plant volatiles: variation in production of cues and in responses of predatory mites. Exp Appl Acarol 22:311-333

Gnanvossou D, Hanna R, Dicke M, Yaninek SJ (2001) Attraction of the predatory mites Typhlodromalus manihoti and Typhlodromalus aripo to cassava plants infested by cassava green mite. Entomol Exp Appl 101:291-298

Gnanvossou D, Hanna R, Dicke M (2003) Infochemical-mediated niche use by the predatory mites Typhlodromalus manihoti and T. aripo (Acari: Phytoseiidae). J Insect Behav 16:523-535

Grostal P, O'Dowd DJ (1994) Plants, mites, and mutualism: leaf domatia and the abundance and reproduction of mites on Viburnum tinus (Caprifoliaceae). Oecologia 97:308-315

Hanna R, Onzo A, Lingeman R, Yaninek JS, Sabelis MW (2005) Seasonal cycles and persistence in an acarine predator-prey system on cassava in Africa. Pop Ecol 47:107-117 
Maeda T, Takabayashi J (2001) Production of herbivore-induced plant volatiles and their attractiveness to Phytoseiulus persimilis (Acari: Phytoseiidae) with changes of Tetranychus urticae (Acari: Tetranychidae) density on plant. Appl Entomol Zool 36:47-52

Magalhães S, Janssen A, Hanna R, Sabelis MW (2002) Flexible antipredator behaviour in herbivorous mites through vertical migration in a plant. Oecologia 132:143-149

Norton AP, English-Loeb GM, Belden E (2001) Host plant manipulation of natural enemies: leaf domatia protect beneficial mites from insect predators. Oecologia 126:535-542

Onzo A, Hanna R, Zannou I, Sabelis MW, Yaninek JS (2003) Dynamics of refuge use: Diurnal, vertical migration by predatory and herbivorous mites within cassava plants. Oikos 101:59-69

Price PW, Bouton CE, Gross P, McPheron BA, Thompson JN, Weiss AE (1980) Interactions among three trophic levels: Influence of plants on interactions between insect herbivores and natural enemies. Annu Rev Ecol Syst 11:41-65

Rozario SA (1995) Association between mites and leaf domatia: evidence from Bangladesh, South Asia. J Tropic Ecol 11:99-108

Sabelis MW, Janssen A, Bruin J, Bakker FM, Drukker B, Scutareanu P, van Rijn PCJ (1999a) Interactions between arthropod predators and plants: a conspiracy against herbivorous arthropods? In: Bruin J, van der Geest LPS, Sabelis MW (eds) Ecology and evolution of the acari. Kluwer, The Netherlands, pp 207-229

Sabelis MW, van Baalen M, Bakker FM, Bruin J, Drukker B, Egas M, Janssen A, Lesna I, Pels B, van Rijn PCJ, Scutareanu P (1999b) Evolution of direct and indirect plant defence against herbivorous arthropods. In: Olff H, Brown VK, Drent RH (eds) Herbivores: between plants and predators. Blackwell Science, Oxford, UK, pp 109-166

Sabelis MW, van Baalen M, Bruin J, Egas M, Jansen VAA, Janssen A, Pels B (1999c) The evolution of overexploitation and mutualism in plant-herbivore-predator interactions and its impact on population dynamics. In: Hawkins BA, Cornell HV (eds) Theoretical approaches to biological control. Cambridge University Press, Cambridge, UK, pp 259-282

Sabelis MW, Janssen A, Kant MR (2001) The enemy of my enemy is my ally (enhanced perspective). Science 291:2104-2105

Sabelis MW, van Rijn PCJ, Janssen A (2005) Fitness consequences of food-for-protection strategies in plants. In: Wäckers FL, van Rijn PCJ, Bruin J (eds) Plant-provided food and herbivore-carnivore interactions. Cambridge University Press, Cambridge, UK, pp 109-134

SAS (2003) The SAS System for windows, Version 9.1. SAS Institute Inc, Cary, NC.

Walter DE, O’Dowd J (1992) Leaves with domatia have more mites. Ecology 73:1514-1518

Yaninek JS, Hanna R (2003) Cassava green mite in Africa-a unique example of successful classical biological control of a mite pest on a continental scale. In: Neuenschwander P, Borgemeister C, Langewald L (eds) Biological control in IPM systems in Africa. CABI, Wallingford, UK, pp 61-75 